\section{RUINA Y MEMORIA}

\author{
Enrique Gavilán Domínguez \\ Profesor Titular. Dpto. de Historia Medieval. \\ Universidad de Valladolid \\ egavilan@fyl.uva.es
}

\title{
RUIN AND MEMORY
}

\begin{abstract}
This article approaches the power of theatre to explore central mechanisms in such a theatrical society as nowadays', starting from a specific genre: some historical theatre, the celebration of the past in the same place where it took place, that is to say, the representation of the memory of the place. It is about the ambiguity that is implicit in the situation and two quite different forms of dealing with it: conmemorative ceremony working for an identity affirmation or the profiting of the irony that lies inside the theatrical gesture in order to unmake memory's tricks.
\end{abstract}

KEY WORDS: Theory of history, theatre, memory, patrimony.

No hace falta declararse adepto de Adorno, Hegel, Lukacs o Heidegger, para repetir una obviedad: el arte es, entre otras cosas, un medio de conocimiento. Eso no significa que deba estar al servicio de otro discurso, el propiamente teórico, como ilustración, cantera o banco de pruebas. Afirmar el papel cognoscitivo del arte no significa sostener que sus "resultados" deban traducirse a un lenguaje formal más depurado. Su relevancia como medio de conocimiento no consiste en proporcionar la materia bruta para que otras disciplinas lo refinen y lo conviertan en teoría. El arte es el medio donde ese conocimiento surge y se realiza. La revelación más importante que encierra un cuarteto de cuerdas no puede reducirse a un conjunto de proposiciones separadas de la música, de la misma manera que su composición no es un derivado inmediato de las circunstancias biográficas en que surgió, cuyo conocimiento desvelaria el significado de sus sonidos. Esto no supone defender que la escucha o la ejecución deba realizarse en un estado irreflexivo; todo lo contrario. El adorniano "pensar con los oídos" (Adorno, 2003, 187) encierra la fórmula exacta para enfrentarse con cualquier forma artística en busca de conocimiento'.
RESUMEN: Se aborda la capacidad del teatro para explorar mecanismos centrales en una sociedad tan teatralizada como la actual, a partir de un género específico: cierto teatro "histórico", la celebración de un episodio del pasado en el mismo lugar donde ocurrió, es decir, la representación de la "memoria del lugar". Se trata la ambigüedad implícita en la situación, y dos formas muy distintas de manejarla: ceremonia conmemorativa al servicio de la afirmación de una identidad, o aprovechamiento de la ironía implícita en el gesto teatral para desmontar las trampas de la memoria.

PALABRAS CLAVE: Teoria de la historia, teatro, memoria, patrimonio.

"... a mediated and conscious prayer that achieves self-consciousness in its failure" Paul de Man, "Heidegger's Exegeses of Hölderlin"

En lo que sigue exploro un ejemplo de cómo en ocasiones el teatro revela mejor aquello que otras disciplinas teóricas exploran. El drama puede ayudar a entender de un modo único la teatralización de un mundo que se presenta cada vez más como un gigantesco espectáculo constituido por una serie interminable de puestas en escena superpuestas. Quizás el escenario no pueda explicar las raíces de la teatralidad dominante con la claridad y precisión del sociólogo, el psicólogo o el experto en comunicación, pero ofrece un espacio privilegiado para experimentarla y comprenderla de otra forma. Incluso en ocasiones lo hace, no a través de la serie canónica que conduce a la catharsis (anamnesis, peripeteia y catástrofe), sino directamente a través de la náusea.

\section{LAS RAÍCES DE LA TEATRALIZACIÓN}

Consecuencia paradójica de la globalización, el presente vive una necesidad acentuada de identidades; se aferra a ellas como dique frente a la imparable descomposición de 
las viejas realidades. Hoy todo tipo de grupos se esfuerza en acentuar sus diferencias imaginando una personalidad tan sólida como irrepetible. Las múltiples identidades presentan coloraciones religiosas, nacionales, locales, raciales, sociales o de género. Tienden a legitimarse defendiendo su supuesta antigüedad -redescubierta, revalorizada, o simplemente inventada. El frenesí nace del vértigo ante una globalización que transforma y disuelve todo a su paso, y lo hace a una velocidad creciente. Sólo las fronteras imaginarias de unas identidades bien marcadas parecen atenuar la angustia. El dique se levanta así con la naturalidad de las formaciones neuróticas que protegen de amenazas tan oscuras como invencibles.

También ha cambiado el modo de construir y articular la identidad (Schulze, 1999). Una estructura de clases cada vez más desdibujada deja de ser la fuente princial de reconocimiento (Bourdieu, 1979; Beck, 1986). En la sociedad del bienestar el ideal de la realización individual se generaliza, convertido en fenómeno de masas (Schulze, 1999, 11 s.). Los grupos tienden a articularse de otra forma, principalmente a través de sus estilos de vida. Por otra parte, la condición postmoderna desintegra las certezas que otrora podian establecer un límite objetivo a los desplazamientos en el escenario social. Se hace posible un juego de roles con una libertad mayor que nunca. Uno puede elegir el papel que se ajusta mejor a sus deseos o necesidades sin otra limitación que el reconocimiento de los otros. Se produce así un despliegue confuso y fluctuante de identidades, que acentúa la teatralización del presente. La sociedad acepta complaciente la táctica postmoderna del "como si" y el teatro se convierte en norma ${ }^{2}$. La identidad se pone en escena como way of life. La moda se convierte en símbolo del presente. La realidad se convierte así en un inmenso escenario, un mundo intensamente teatralizado. El impacto de los mass media contribuye a acentuar todavía más esa tendencia. Los acontecimientos políticos, deportivos, culturales, religiosos, no son simplemente difundidos sino que son teatralizados para esos medios; en cierta medida, son creados por estos (Vaßen, 2001).

En el carnaval postmoderno interviene otro factor. Cada vez más las autoridades locales y nacionales tienden a organizar eventos que satisfagan la insaciable necesidad de diversión que genera la sociedad del ocio, con predilección por aquellos que combinan turismo, cultura e identidad. El resultado es una política singular que contribuye aún más a la teatralización general. Vivimos la era del parque temático, de la conmemoración como atractivo turístico, de la teatralizacion del pasado como aliño del ocio. El "mercado medieval", carnaval, turismo y comercio hermanados en una institución "tradicional", se ha convertido en el emblema de política cultural para algunos políticos esclarecidos ${ }^{3}$.

Sin embargo, el desarrollo de una cultura de eventos no deriva de la frivolidad o la incompetencia intelectual de sus organizadores, sino de una necesidad profunda de la misma sociedad. Para realizar su identidad los sujetos deben ponerse en escena. Esos espectáculos tan hiperteatrales pueden resultar toscos, estúpidos o grotescos, pero en ellos se encierra menos engaño que juego ${ }^{4}$.

En ocasiones el evento incluye la representación dramática del episodio conmemorado. La variedad de formas de realizarlo es casi inagotable: en tono solemne o de farsa; con un guión elaborado o dejando un margen a la improvisación; con actores profesionales o permitiendo la intervención del público, etc.

El interés que este género tiene para entender mejor la dinámica social en la que se inserta, deriva de cierta ambigüedad que lo habita. Estas representaciones, incluidas sus formas más toscas, comparten dos características: reflexividad e ironía. Ambos rasgos aparecen tanto en la celebración teatral de episodios heroicos, gloriosos, o simplemente antiguos, como en gestas menos relevantes, o tan inquietantes como "la quema de la bruja" ese momento culminante del "mercado medieval", la restauración ficticia de la pena capital por el fuego, para regocijo del respetable público ${ }^{5}$.

En una sociedad teatralizada el teatro se convierte en terreno privilegiado para investigar la dinámica de la puesta en escena. A diferencia de lo que ocurre en la vida cotidiana, donde los papeles se encarnan o se contemplan con inconsciente naturalidad, el escenario se presenta como lo que es, un dispositivo para la representación, un espacio donde lo real se sujeta a la modalidad del "como si". Ese margen abre la distancia que permite analizar la dramaturgia que envuelve hoy la vida social ${ }^{6}$.

En segundo lugar, en cualquier representación escénica hay una inevitable dualidad, la propia del signo teatral: un 
cuerpo dividido entre lo que hace y aquello a lo que alude, siempre en sí mismo y más allá de sí mismo, presencia y representación (Fischer-Lichte, 2004, 135 ss.). El doble plano entre lo que ocurre y lo que se representa engendra una ironía implícita; el espectáculo puede aprovecharla o no. En todo caso, no puede eliminar su sombra de la mirada del espectador, lo que a veces produce una comicidad indeseada (la carcajada ante la mamarrachada envuelta en solemnidad). Esa dualidad se acentúa cuando, como en los eventos que considero, se representa una peripecia histórica. La escisión temporal no puede esconderse ${ }^{7}$. La ironía implícita, derivada de la dualidad inocultable de presente y pasado, se manifiesta aquí con más claridad, incluso en las formas más respetuosas de dramatizar la historia ${ }^{8}$.

Aquí me interesa una forma particular de esas representaciones: las que se realizan en el mismo lugar donde supuestamente ocurrieron los episodios escenificados. Por su naturaleza estos espectáculos otorgan un relieve particular al espacio. La atmósfera se convierte en el elemento que da sentido a la representación. Ésta adquiere el aura de lo único, de aquello que sólo puede celebrarse con "autenticidad" en ese lugar, porque sólo allí reside su "verdad"; viene del aura que, como fantasma insepulto, envuelve unas ruinas, reales o imaginarias. En cierta medida, esos espectáculos ponen en escena la "memoria del lugar". La repetición no agota su energía espiritual; al contrario, el elevado ordinal que anuncia la celebración proporciona un timbre de nobleza suplementaria al evento. Incluso aquellos que se organizan por primera vez suelen ir unidos al deseo expreso de que se asienten y se conviertan en inicio (jo recuperación!) de una tradición secular.

Suele tratarse de espectáculos modestos en lo artístico, pero envueltos en la pompa que suscita el adjetivo "histórico". Existen innumerables ejemplos que celebran esa memoria con el prosaico fin de hacer prosperar la hostelería local, o justificar todo tipo de derechos ancestrales, identidades diferenciadas, superioridades nacionales, primacias locales, etc. Pero no son las formas abiertamente celebratorias las que me interesan aquí -poner de relieve su estupidez apenas exigiría mucho más de media docena de líneas-, sino las que indagan sobre la herida del tiempo y los mecanismos del recuerdo.

El teatro puede analizar, explicar o criticar la manía de las celebraciones, desenmascarar a quienes las inspiran, las aprovechan o las disfrutan, pero no puede hacerlo de una forma más precisa, exhaustiva o inteligente que un discurso que aborde la misma cuestión desde una perspectiva puramente teórica. Y sin embargo, su crítica resulta a veces más incisiva. En la dramatización de la memoria de un lugar esa posibilidad se refuerza. No se trata sólo de la intensidad de la experiencia, sino de cómo el mismo teatro presenta aquello que re-presenta, es decir, el lugar donde se celebra. En otros dramas se muestra aquello que se intenta contar, criticar o analizar, pero se hace a través de signos que remiten más allá de sí mismos. Aquí se representa el mismo escenario, al tiempo sujeto y objeto, símbolo y presencia. El bucle reflexivo se cierra, aprisionando al espectador en el lugar inesperado. De pronto el público descubre que su propia imagen se apunta en el espejo.

Finalmente, en el teatro es posible una extraordinaria ambigüedad hacia su objeto. Como en el caso que analizaré, el drama puede afirmar y negar al mismo tiempo, cuestionar, por ejemplo, el hechizo de la memoria asociada a un lugar, y aprovechar esa magia que desenmascara, como si fuera real.

\section{Playrec}

Mayo de 2006, en Valladolid la compañía francesa KompleXKapharnaüm estrenaba una obra singular, Playrec, espectáculo inaugural y principal atractivo del Festival de Teatro y Artes de Calle ${ }^{9}$. El drama se desarrollaba en una vieja estación abandonada, "La esperanza", parte de una línea desahuciada, el ferrocarril de Ariza. El lugar no sólo servía de escenario sino que se convertía en objeto principal del espectáculo. Éste se presentaba como una exploración de la memoria de ese espacio. En la etapa preparatoria los colaboradores de la compañía indagaron sobre la estación. Buscaron y entrevistaron a antiguos empleados del ferrocarril, que vivían en un barrio próximo. Esas conversaciones, grabadas en vídeo, constituirian la materia sobre la que iba a girar la representación.

Con este planteamiento, el espectáculo parece alejarse de la pomposa celebración de las glorias del pasado. La exaltación de la memoria de una vieja estación abandonada parece demasiado alejada de las habituales hazañas bélicas, artísticas, o políticas que centran ese tipo de 
eventos. Pero razonar así es perder de vista la lógica de las conmemoraciones localistas. Nada está libre de su pulsión conmemorativa. Se puede celebrar desde la participación de un vecino en una expedición al Monte Perdido hasta el centenario de la construcción de unos vetustos urinarios públicos, recientemente remozados por un diligente alcalde, pasando por la inauguración de una calle con el nombre del artesano que mejoró el mecanismo del garrote vil, uno de cuyos hijos vivió en la localidad. Desgraciadamente hoy acaba por ser indistinguible el estilo, el tono o el gesto de la exaltación de la II República de los fastos cerveceros del centenario de la Reina Católica.

Incluso la celebración de los perdedores resulta a veces más adecuada para dar libre curso a la manía conmemorativa. Cuando los excesos celebratorios empiezan a agotar su eficacia, acontecimientos menos heroicos conservan cierta credibilidad. Por otra parte, la exaltación de la memoria de la vieja estación en desuso servía a la perfección a la imagen de la ciudad. En la intención de sus organizadores, tal como la airearon en la prensa local, la obra dibujaba un puente entre el glorioso pasado de Valladolid y su esplendoroso futuro. La modesta estación se convertía en símbolo de viaje, aventura y prosperidad en una ciudad bien enraizada en la historia: la próxima llegada del AVE como eco de otra aventura gloriosa, el Quinto Centenario del fallecimiento de Colón, celebrado días antes en la Plaza Mayor con un colosalismo sin precedentes.

En Playrec los actores quedaban reducidos a manipuladores de una imponente batería de aparatos electrónicos, ordenadores, vídeos, impresoras, etc., desde los que se proyectaban y trastornaban las imágenes de las entrevistas grabadas, multiplicadas en paredes, pantallas y monitores. La estación se poblaba con el eco de sus antiguos habitantes. Los espectadores, sumidos en la penumbra, como en un espectral cine al aire libre, quedaban envueltos en esa proliferación desconcertante. Las voces grabadas dominaban el espacio. Un empleado del ferrocarril, Fortu, hablaba de sus recuerdos, pero las imágenes se repetían una y otra vez hasta adquirir un sentido inesperado. El mensaje se deterioraba hasta lo grotesco, mientras el personaje conservaba siempre la misma satisfacción incongruente del jubilado que disfruta de su momento de gloria. El día del estreno se había invitado a los protagonistas, que circulaban muy ufanos por la vieja estación, fascinados por su propia imagen. La circunstancia añadía un inesperado toque de farsa, como una parodia de los estrenos hollywoodenses. La ceremonia de la estación de Ariza permitía advertir con más claridad que la alfombra roja de las galas californianas el narcisismo de un mundo en el que los actores se han convertido en complacidos espectadores de su propia grandeza.

Cuando el espectáculo avanzaba, la atención, fatigada ante el relato vacío de las pantallas, se desplazaba hacia el elemento dominante de la puesta en escena, no las imágenes que repetían los viejos relatos, sino la multiplicación de artefactos destinados a guardarlos. El espectador descubría con asombro que en el edificio silencioso de la estación el elemento central del drama era una proliferación incongruente de medios para conservar y transformar su memoria.

Playrec es en cierta medida un drama de ciencia ficción en torno al recuerdo. El espectáculo articula una disposición temporal muy complicada. Representa un futuro que mira el presente de la estación donde se encuentra el público, como si fuese pasado, una impresión que se refuerza por tratarse de un lugar abandonado, marcado por el signo de lo pretérito. A pesar de la ambigüedad de la puesta en escena, las historias se presentan como proyectadas desde ese futuro imaginario e indeterminado en el que habrian proliferado los medios de guardar, estudiar y manipular los recuerdos, en realidad, no estos sino su relato ${ }^{10}$. Sin embargo, en el escenario en penumbra sólo estamos nosotros mismos, los espectadores (¿en qué tiempo?), rodeados por sombras en apariencia ajenas a nosotros (los actores) que manejan las imágenes con una pasión enfermiza. Nos vemos en la mirada futura que proponen los actores de Komplex; pero somos nosotros los que estamos alli, quienes hemos acudido a reconocer esa memoria. Nos convertimos así en sujeto y objeto de la representación, en un presente que se constituye a la vez como tiempo futuro representado y como pasado imaginado, sostenido en una mirada (la que nombra la etimología de "teatro") que observa el reflejo de otras miradas que manipulan imágenes donde se relatan recuerdos.

La complejidad del elemento temporal se acentúa por otra circunstancia. El espectáculo se estructura en torno a un doble movimiento. Por una parte, la estación de Ariza no se representa sino que se presenta; su materialidad ocupa el espacio dramático de lo imaginario, un hecho acentuado 
por la iluminación, que subraya desde el primer momento el protagonismo del edificio. El espacio se convierte en el anclaje temporal que une el presente con los diversos pasados a los que el drama alude, y con el futuro del tiempo diegético. Por otra parte, Playrec vacía la realidad teatral en dirección al simulacro: los actores son desplazados a los márgenes de la representación, y el centro queda ocupado por las imágenes de los ferroviarios jubilados, eco reciente que la trama presenta como remoto, alejando el presente de los actores hacia un imaginario futuro. En cierta medida ese vaivén que acerca y aleja el tiempo consigue anularlo en la representación.

El teatro es un medio que favorece la reflexividad, permite una estructura en bucle, como la de Playrec: unos personajes del futuro miran cómo otros personajes miraban su pasado. En el escenario es casi inevitable que surja una forma de teatro dentro del teatro, no simple representación, sino espectáculo de cómo se mira, o como en este caso, representación de cómo se produce, controla y manipula una representación, en cuyo centro se encuentra atrapado el espectador.

Ahora bien, si se atiende a la respuesta de quienes acudieron al evento, con una mezcla de curiosidad y orgullo localista, el espectáculo resultó un completo fracaso. En cierta forma en esa decepción se encerraba el acierto artístico del proyecto, la amarga verdad que Playrec escondia. Komplex provocaba la desbandada. Sin embargo, a pesar de la decepción, hasta el más crítico de los asistentes hubiese reconocido su sorpresa. Lo que se encontraba en la estación de Ariza podía parecerle incomprensible, irritante y aburrido, pero sin duda también completamente inesperado. La penumbra favorecía la discreción del imparable goteo de fugitivos de la estación. Al cabo de no demasiados minutos la mayoría del público había abandonado aquel desconcertante galimatías. Ese vaciamiento resultaba cómodo para quienes se quedaban. La excesiva concentración del comienzo hacía aún más incomprensible el espectáculo. Podría haberse acusado a los organizadores de "publicidad engañosa". Con sus reclamos coloristas habian desbordado el espacio disponible. Para explorar la memoria de un lugar, atiborrarlo de gente no parece la estrategia más acertada, aunque pudiera serlo si se trataba de exaltar el esplendoroso presente de la ciudad donde 500 años antes había muerto Colón. Por otra parte, el exceso de asistentes se integraba bien en la lógica de Playrec; el efecto perverso en las condiciones de recepción contribuía a la destrucción de la nostalgia, a la mortificación del recuerdo, y de eso se trataba.

\section{EL PODER DE LA RUINA}

Playrec pone en escena los recuerdos de un espacio en escombros, La Esperanza, estación abandonada del ferrocarril de Ariza; KompleXKapharnaüm hace presentes los fantasmas que encierra esa ruina, los teatraliza. El espectáculo se presenta como indagación en la "memoria de un lugar". Cuando se utiliza esa expresión se efectúa un juego de lenguaje tan sugestivo como engañoso"11, aunque, como ocurre aquí, puede encerrar cierta verdad. Un espacio inanimado carece de memoria porque no puede recordar, pero puede convertirse en sostén de la memoria de otros, punto de apoyo de las historias que dan sentido a esa ruina. "No sólo es que [los lugares] afirmen y hagan creíble el recuerdo..., sino que encarnan también una continuidad que supera el recuerdo comparativamente breve de individuos, épocas e incluso culturas" (Assman, 2006, 299).

La ruina sostiene el pasado recordado, narrado o inventado. Su presencia dibuja al mismo tiempo una discontinuidad básica. Apunta la indisimulable diferencia entre pasado y presente, no su continuidad sino la ruptura violenta que los separa. La ruina es el símbolo de la complementariedad de olvido y recuerdo. "Un lugar de memoria (Gedenkort) es lo que queda de algo que ya no existe y ha perdido su valor. Para poder subsistir y seguir teniendo valor, debe contarse una historia que supla el contexto perdido" (Assman, 2006, 309).

KompleXKapharnaüm podía haber optado por "animar" la estación de Ariza, dramatizar las viejas historias, conjurar sus fantasmas, organizar una especie de Mercado medieval ferroviario, a la manera de la solemne entrada de Isabel la Católica en Segovia. Pero su estrategia es radicalmente diferente: no rastrear los recuerdos asociados al lugar para envolverlos en la pompa o la nostalgia, sino ofrecer la memoria "en acto", como proceso de mixtificación inevitable, adición incesante de historias que se transforman y deforman a medida que se cuentan. Komplex "mortifica" la memoria, presentándola, no como un resultado estable, 
sino como proceso inestable que se desarrolla a medida que transcurre el "drama."

Esa línea dramática es una defensa frente a una insidiosa paradoja que encierran las ruinas. "La conservación de esos lugares en aras de la autenticidad significa una inevitable pérdida de autenticidad" (Assman, 2006, 333). El monumento al pasado mixtifica el pasado. Éste no puede ser recordado sin que su sentido se vea alterado. "Quien pone demasiado énfasis en el poder de memoria del lugar corre el peligro en confundir el sitio para los visitantes con el sitio histórico, el de los internados en el campo de concentración [en relación con Dachau]" (ibidem). De ahí el desplazamiento del énfasis en el drama de la estación, desde el parque temático a la exploración del mecanismo de su memoria, de la ruina a la ruinización. Hay una relación -no sé hasta qué punto consciente- entre la dramaturgia de Playrec y los conceptos de ruina y ruinización ó mortificación (Mortifikation) tal como los emplea Walter Benjamin en su análisis del drama barroco (Benjamin, 1991, 353 ss.). En todo caso, resultan provechosos para entender lo que ocurría en la Estación de Ariza.

Según Benjamin, el transcurso del tiempo decanta la verdad de una obra. Aquélla cristaliza cuando ésta se convierte en ruina; su perfil se hace entonces visible. Los escombros ofrecen el secreto escondido de una época; el crítico perspicaz sabe leer el mensaje que encierran los vestigios descompuestos porque en ellos afloran los sueños del pasado. Pero esa verdad puede adivinarse ya antes, en el momento en que la obra surge, porque, escondida bajo el brillo que el tiempo gastará, se encuentra la imagen de su futura ruina. La tarea de la crítica es adivinar la erosión de la historia, provocando un efecto similar (mortificación); desvela así el contenido escondido que sólo aflorará en los despojos demacrados. "Crítica es mortificación de las obras. La esencia [de la crítica] se acerca más a ésta que a cualquier forma de producción. Mortificación de las obras, es decir, no despertar de la conciencia en las vivas -estilo romántico-, sino asentamiento del saber en ellas, en las muertas" (Benjamin, 1991, 357).

Playrec es una mortificación, pero no de la ruina visible - los restos de la estación-, ni de los viejos sueños que albergara antaño -"La Esperanza"-, sino de materiales más modestos: las historias que sobre aquel pasado cuentan y se cuentan hoy sus antiguos habitantes, los relatos que dan sentido a aquel espacio abandonado, la "memoria del lugar". Su verdad radica, no en la ruina de los recuerdos, sino en la "mortificación" de su narración. El trabajo de repetición y manipulación de las historias hace sentir que no existe un sustrato firme, una presencia, que los sostenga. El recuerdo se articula como una serie de relatos planos, siempre repetidos, tan insípidos para otros como jugosos para sus protagonistas. La memoria colectiva se conforma como un juego que combina los materiales más previsibles, los viejos lemas deshilachados asociados a los iconos cinematográficos o deportivos ("Soy de la quinta de Puskas y Di Stefano"), los arquetipos gastados, que desfilan en un mundo de sombras. En Playrec la "memoria viva" no deja de ser un simulacro que otros simulacros mortifican. En realidad, no hay memoria genuina, su falta de densidad es desenmascarada por la repetición.

Komplex construía un espacio lleno de ironía; no el mercado medieval ferroviario que tanto hubiese complacido a unos y otros, sino un parque temático de la memoria y sus excesos, el despliegue abrumador de los modos de conservación, transformación y exhibición del recuerdo, no como exposición estática, sino como proceso dinámico, el despliegue de una antigua estación por la que no circulaban ferrocarriles, sino viejas historias de trenes. Como debería haber ocurrido años atrás con aquellos, éstas se repetían también con fatal sincronicidad. La desproporción entre los imponentes medios desplegados y las historias insignificantes que encerraban permitía advertir mejor su poder de manipulación, metáfora final del funcionamiento de memoria, relato e identidad, el mecanismo básico de cualquier espejo: uno ve la imagen donde no está (Lacan, 1998, 119 ss.).

\section{EL ESPECTADOR COMO ÚNICO ACTOR}

El teatro permite desplegar memoria y espacio de una forma única. Ofrece un modo de percepción singular: la copresencia de actores y espectadores. Saca así del confortable refugio del cuarto de estar, la impotencia emblemática del ciudadano en su sillón. En el drama se encuentra en otro espacio, sujeto a otro ritmo temporal; queda indefenso frente al acontecimiento escénico.

El espectáculo de la estación mortificaba los recuerdos, descarnaba las historias, las torturaba en un continuo pro- 
ceso de repetición, fragmentación y recomposición, pero -y esto es decisivo- lo hacía a medida que las presentaba. El drama estaba, no en las entrevistas grabadas que se proyectaban por doquier, sino en su despliegue en aquellas coordenadas de espacio y tiempo concretas, en el modo en que la proyección múltiple y simultánea encerraba al espectador en un laberinto del recuerdo, frente al que la sola escapatoria era abandonar "La esperanza" y despertar de la pesadilla, o regresar a otra menos insoportable porque se ha hecho habitual.

La nómina de actores no se reducía así a quienes desde las pantallas contaban las viejas historias o a quienes desde los instrumentos de control les obligaban a repetirlas como fragmentos inconexos, sino que incluía a los mismos espectadores. Su papel podría titularse: "Desconcierto frente a la desproporción de la memoria". La tensión dramática derivaba de su dilema: resistir la náusea que provocaba el aburrimiento de lo incomprensible, a la espera de una acción heroica que por sorpresa diese sentido a aquel galimatías, o desertar. Ni los locuaces jubilados ni los "informáticos" silenciosos que regulaban el ritmo de la perorata de Fortu y compañía parecían en condiciones de realizar otro acto que no fuese repetición de lo ya experimentado. Playrec es un trabajo de mortificación, no sólo de las historias de los viejos ferroviarios, sino también de los mecanismos del recuerdo de quienes las contemplan. Al reducirlos a ruina mostraba la verdad que encierran. Por eso resultaba insoportable. En cierta medida la única acción dramática posible era el abandono, un gesto coherente con la celebración de una estación abandonada. Sólo el público podía llegar a ser actor real de aquel drama.

En Playrec el espectador se veía expuesto a la agresión blasfema, al escarnecimiento de una parte escondida de sí mismo, el mecanismo sagrado de recuerdo e identidad. Su lado más íntimo resultaba así vulnerable al ataque. Experimentaba cómo se frustraban las expectativas con que había acudido a la vieja estación, las sensaciones de la larga espera, la contigüidad del espejo inquietante de sus iguales. Las historias asociadas al lugar, los recuerdos de sus antiguos habitantes eran manipulados, mortificados y escarnecidos por una batería de artefactos tan incomprensibles como poderosos, hasta convertir en insoportable una escena en el centro de cuyo espacio estaba él mismo. Su única defensa era entonces la incomprensión o la huida.
Y sin embargo, la representación de KompleXKapharnaüm se desplegaba como una inmensa paradoja. El teatro, el arte de la presencia, se transmutaba en un acontecimiento sin actores, convertidos en sombras, cuya función se reducía a operar sobre la huella de otras sombras. El espacio de la memoria, la estación, se convertía en apoteosis del simulacro. La copresencia se reducía a un desfile de imágenes inconsistentes que se multiplicaban por los muros del escenario de la memoria, imágenes dominados por la repetición y la degradación.

\section{FINAL}

El teatro sucede, ocurre en presente, siempre aqui y ahora. El espectáculo es el acontecimiento mismo, un trastorno irrepetible. Pero a la vez remite más allá de sí mismo, alude, representa, explica, instruye.

En uno de sus comentarios sobre Hölderlin Martin Heidegger escribía: "Lo sagrado regala la palabra y llega en esa palabra. La palabra es el acontecimiento" (Heidegger, 1996, 76). Sin duda no es este el lugar para extenderse sobre la sutileza de ese desdoblamiento de luz y oscuridad que se produce en el fulgor heideggeriano de la verdad, pero si insistir en su parentesco con algo que puede ocurrir en el escenario, ese estar dentro y fuera, mostrarse y ocultarse, ser y representar. Por otra parte, también en el teatro hay un elemento sagrado, una forma de cosmogonía, la creación de un espacio y un tiempo propios en los que el espectador penetra y queda atrapado.

Esa característica del drama, su manifestación como acontecimiento, se da en otras artes, como la música y la plástica más vanguardistas, aunque sólo como posibilidad que en la mayoría de los casos no es aprovechada. Sin embargo, hoy constituye la tendencia dominante en la escena. No es casual que cuando la sociedad se teatraliza, el teatro gire hacia lo performativo.

El teatro no hace presente el pasado, no es una máquina del tiempo, sino una máquina que permite experimentar el funcionamiento del tiempo. Como en el ejemplo analizado, puede hacer presente la misma dinámica del recuerdo, deconstruirla a medida que se despliega, reducir a comedia el drama de la identidad. Lo que Playrec consigue decir 
sobre la memoria puede ser devastador. No existe un sustrato firme, una presencia, que la sostenga. Pero todo eso podría encontrarse en un texto de psicología, de sociología o de historia oral, incluso formulado con mayor precisión, elegancia o complejidad. Pero el valor del espectáculo no radica en el acierto de esas tesis, sino en lo que sucedía en la estación de Ariza, en esa experiencia irreversible que el espectador construía.

El escenario acentúa la reflexividad de la percepción; ésta se convierte en parte del mismo acontecimiento. Al reconocer en el espectáculo las trampas de la memoria, uno se percibe a sí mismo descubriéndolas, y eso pasa a formar parte de la misma peripecia dramática, lo que da un nuevo sentido a la percepción y la intensifica, en una acción recíproca de una riqueza insólita: mi percepción de mi mismo percibiendo me hace vivir el drama de otra forma, que tiende a ser aún más intensa, y esto intensifica la conciencia de cómo lo estoy entendiendo. "Las representaciones teatrales crean una situación límite. Colocan... a los espectadores... en una situación de crisis. La experiencia de esa crisis como... desestabilización de la experiencia del yo, de lo otro y del mundo... La experiencia estética en el teatro... puede describirse con más precisión como experiencia de umbral" (Fischer-Lichte, 2005, 22).
Todo esto, el trabajo con la presencia, su carácter de acontecimiento, la reflexividad acentuada, la participación del espectador, etc., puede encontrarse en cualquier forma de teatro. Sin embargo, un espectáculo como Playrec, que explora in situ la memoria de un lugar, está en condiciones de aprovechar de otra forma los desplazamientos de tiempo y espacio que ocurren en el drama. La ambigua presencia del edificio, espacio dramático y vestigio real, permite crear ese laberinto del tiempo donde el espectador experimenta su propia pérdida, un desconcierto que le empuja a escapar, a buscar el suelo firme de su paisaje cotidiano, cuyos mecanismos son ciegos a los agujeros de la identidad que se abrian en la vieja estación abandonada.

Sería un error intentar utilizar el teatro como fármaco para aliviar el vértigo del presente. Al igual que el psicoanálisis, no puede curar, sino que en el mejor de los casos ayuda a aceptar lo incurable. Como remedio, el escenario debería ser más bien un recurso homeopático: no instrumento para afirmar una identidad, sino para socavarla mostrando precisamente la inconsistencia que habita su naturaleza teatral, iluminación de las grietas que anuncian la ruina.

\section{NOTAS}

1 "Las obras de arte... comunican a través de aquello que no aparece en los otros sistemas de comunicación: con la percepción. Mientras sólo podemos comunicar a través de la percepción, el arte comunica con la percepción" (Rebentisch, 2003, 90).

2 "En América el cine es verdad porque todo el espacio, todo el modo de vida son cinematográficos... La vida es cine" (Baudrillard, 1986, 98).

3 A veces esa orientación recibe sello institucional. En la autonomía donde resido, Castilla-León, cultura y turismo se integran en el mismo departamento. Si esa instrumentalización resulta plausible desde el punto de vista de la promoción turística, es perversa desde el punto de vista de la cultura. La iniciativa resulta tan funcional que ha sido adoptada recientemente por el ayuntamiento de mi ciudad.

4 En francés, inglés o alemán, la misma palabra (jeu, play, spiel) ha servido para designar "obra de teatro" y "juego".

5 En la Web donde promociona sus espectáculos un grupo dedicado a los mercados medievales dice sobre su "quema de la bruja": "[La bruja] es quemada en el escenario, a la vista de todos los presentes, en un número de magia espectacular... El público participa de una forma lúdica y expontánea $[s i c] . . . "$, etc. La misma compañía organiza otra variante, con mayor "rigor histórico" y "apoyo literario": la Quema del hereje.
Recibido: 31 de agosto de 2007

Aceptado: 30 de septiembre de 2007 
6 En la existencia cotidiana "lo real se presenta como... lo efectivo y auténtico, pero su lado de verdad queda oculto, alterado por lo inmediatamente perceptible. La dura costra de la naturaleza y el mundo cotidiano hacen que el espíritu alcance la idea con más dificultad que en las obras de arte" (Hegel, 1992, 23) precisamente porque estas se presentan como ficticias.

7 Como subraya Jutta Eming, la grotesca Disneylandia de museo transmite también una lección que todo espectador entiende: el pasado es irrecuperable y debe ser construido como puesta en escena (Eming, 2001, 352-353). Los risibles tableaux vivants del parque temático encierran un cuestionamiento inquietante de la hegemonía del discurso histórico. El gesto de olímpico desprecio con que el historiador "serio" los descalifica sólo pone de relieve su ceguera para entender las raíces de la crisis de su propia disciplina.

8 Por esa razón, no suelen escenificarse episodios históricos decisivos para quienes los conmemoran; el peligro de carnavalización lo desaconseja. En esos casos se recurre a himnos, coronas de flores, discursos de exaltación, etc.

9 En "La carpa o la vida" (Gavilán, 2008) analizo la relación con el espacio que se establece en el espectáculo. Aquí aprovecho algunas ideas de aquel texto.

10 Sin duda Playrec no es el primer drama que recurre a la ciencia-ficción para escindir el tiempo diegético en "pasado" (la obra interior) y un "futuro" imaginario desde el que asistimos al relato escénico, una estructura de teatro dentro del teatro en la que ambos mundos se pre- sentan como reales. La coexistencia se explica por un avance científico que permitiria viajar en el tiempo, etc. El tragaluz es un buen ejemplo. Sin embargo, lo más interesante de la comparación con el espectáculo de Komplex no está en las diferencias de sentido (en Buero la recuperación de un pasado reprimido -la Guerra Civil-, como medio de otorgarle una sanción moral), sino en cómo el espacio de la estación afecta a la estructura temporal de Playrec y cómo se aprovecha el elemento "real" -los relatos de los empleados, que pertenecen al mismo mundo y que pueden circular entre el público-, para implicar a los espectadores.

11 "Quien habla de 'memoria de lugares' se sirve de una fórmula tan cómoda como sugerente. Cómoda porque deja en el aire si se trata de un genitivo objetivo, una memoria de los lugares, o un genitivo subjetivo, es decir, una memoria que está localizada en los lugares; el giro es sugerente porque transmite la posibilidad de que los lugares puedan convertirse en sujetos, portadores del recuerdo, y que dispongan de una memoria que va más allá que la de los hombres" (Assman, 2006, 298).

\section{OBRAS CITADAS}

Adorno, Theodor W. (2003): "Die gewürdigte Musik", Gesammelte Schriften, vol. XV, Frankfurt a.M., Suhrkamp.

Assmann, Aleida (2006): Erinnerungsräume. Formen und Wandlungen des kulturellen Gedächtnisses, Munich, Beck.

Baudrillard, Jean (1986): Amérique, París, Grasset.
Beck, Ulrich (1986): Risikogesellschaft. Auf dem Weg in eine andere Moderne, Frankfurt a.M., Suhrkamp.

Benjamin, Walter (1991): Ursprung des deutschen Trauerspiel, Gesammelte Schriften vol. I, 1, Frankfurt a.M., Suhrkamp.

Bourdieu, Pierre (1979): La distinction: critique sociale du jugement, Paris, Les Editions de Minuit.

Eming, Jutta (2001): "Living History", en Nicolas Pethes (ed.), Gedächtnis und Erinnerung. Eine interdisziplinäres Lexikon, Hamburgo, Rowohlt.

Fischer-Lichte, Erika (2004): Ästhetik des Performativen, Frankfurt a.M., Suhrkamp.

Fischer-Lichte, Erika (2005): "Aufführung", en Metzler Lexikon Theatertheorie, Stuttgart, Metzler.

Gavilán, Enrique (2008): "La carpa o la vida. El espacio del teatro de calle", en Bañuls, J. Vte.; De Martino, Fr. y Morenilla, C. (eds.), Teatro y sociedad en la Antigüedad Clásica: las relaciones de poder en época de crisis, Bari, Levante.

Hegel, Georg Wilhelm Friedrich (1992): Vorlesungen über die Ästhetik, vol. I, Frankfurt a.M., Suhrkamp.

Heidegger, Martin (1996): Erläuterungen zu Hölderlins Dichtung, Frankfurt a.M., Klostermann.

Lacan, Jacques (1998): Le seminaire $I$. Les écrits techniques de Freud, París, Seuil.

Rebentisch, Juliane (2003): Ästhetik der Installation, Frankfurt a.M., Suhrkamp.

Schulze, Gerhard (1999), Kulissen des Glücks. Streifzüge durch die Eventkultur, Frankfurt a.M., Campus Sachbuch.

Vaßen, Florian (2001): "Kunstform Theater und alltägliche Theatralität in der Mediengesellschaft", Zeitschrift für Literaturwissenschaft und Linguistik, Jh. 31, Heft 124. 